\title{
Mechanisms of inhibiting human leukemia cell lines by serum of rats treated with compound banmao capsule
}

\author{
LI LI $^{1}$, LIXIA ZHU ${ }^{1}$, JINGJING ZHU ${ }^{1}$, XIAOFEN FAN ${ }^{2}$ and XIUJIN YE ${ }^{1}$ \\ Departments of ${ }^{1}$ Hematology and ${ }^{2}$ Traditional Chinese Medicine, The First Affiliated Hospital, \\ School of Medicine, Zhejiang University, Hangzhou, Zhejiang 310003, P.R. China
}

Received October 9, 2015; Accepted March 17, 2017

DOI: $10.3892 / \mathrm{ol} .2017 .6688$

\begin{abstract}
Compound banmao capsule (CBC) is a traditional Chinese medicinal formula composed of extracts from 11 organisms. The present study investigated the mechanism of $\mathrm{CBC}$ on the biological behavior of human leukemia cell lines using seropharmacological methods. CBC-containing rat serum was prepared by intragastrical administration of CBC to rats. The proliferation of human leukemia HL60 and K562 cell lines was assayed by measuring cell viability with the 3-(4,5-dimethylthiazol-2-yl)-5-(3-carboxymethoxypheny 1)-2-(4-sulfophenyl)-2H-tetrazolium method, while cell cycle distribution and the rate of apoptosis were evaluated with flow cytometry. The mRNA expression of vascular endothelial growth factor A (VEGF-A) and chemotactic and inflammatory genes in human leukemia cell lines was examined using reverse transcription quantitative-polymerase chain reaction methods. It was revealed that the proliferation of K562 and HL60 cells was significantly inhibited by the CBC-containing rat serum at $72 \mathrm{~h}$. The $\mathrm{CBC}$-containing serum also promoted the apoptosis of K562 and HL60 cell lines. The CBC-containing serum altered the cell cycle progression of K562 and HL60, increasing the proportion of the cells in G1 phase and decreasing the proportion of the cells in S phase. Attenuated expression of VEGF-A and a decreasing trend in the expression of chemotactic and inflammatory genes were identified following treatment with CBC-containing serum in HL60 and K562 cells. In conclusion, CBC-containing serum exerted an inhibitory effect on the growth of K562 and HL60 cells by decreasing cellular proliferation, promoting apoptosis and cell cycle arrest, and decreasing the expression of VEGF-A, and chemotactic and inflammatory genes.
\end{abstract}

Correspondence to: Dr Xiujin Ye, Department of Hematology, The First Affiliated Hospital, School of Medicine, Zhejiang University, 79 Qingchun Road, Hangzhou, Zhejiang 310003, P.R. China E-mail: yxjsunny@zju.edu.cn

Key words: chemotactic and inflammatory genes, HL60, K562, seropharmacology, vascular endothelial growth factor A

\section{Introduction}

Leukemia is the cancer of the body's blood-forming tissues, including the bone marrow and the lymphatic system (1). Despite advances in the understanding of the etiology of leukemia and the sub-classifications of the disease (2), the number of treatment alternatives for patients remain limited. Bone marrow transplantation has curative potential; however, this is only an option for a limited number of patients. Typical chemotherapy may be associated with poor efficacy, high toxicity and a limited survival time benefit (3). Traditional Chinese medicine (TCM), which originates from botanical, animal and mineral sources, has provided a rich resource for anticancer drug discovery that is attracting an increasing amount of interest (4).

Compound banmao capsule (CBC) is a traditional Chinese medicinal formula composed of extracts from 11 organisms, including Mylabris phalerata (banmao), Panax ginseng (radix ginseng), Astragalus membranaceus (radix astragali), Eleutherococcus senticosus (radix acanthopanax senticosus), Rhizome sparganii, Scutellaria barbata, Curcuma zedoaria, Cornus officinalis, Ligustrum lucidum ait, Herba galii aparinis and Glycyrrhiza glabra L. (radix glycyrrhizae). As the main component of $\mathrm{CBC}$, banmao extract shows potential for anti-tumor capability as it has previously been demonstrated to directly kill tumor cells (5). Banmo has therefore been applied for the treatment of primary liver and lung cancer, rectal carcinoma, malignant lymphoma and gynecological tumors (5). However, the underlying mechanism for anti-tumor activity by $\mathrm{CBC}$ remains unknown.

Seropharmacology is a novel method for pharmacological study on Chinese materia medicain vitro using drug-containing serum (6). The essence of seropharmacology is the administration of drug to an experimental animal (for example, a rabbit, rat or mouse), followed by harvesting the animal blood and conducting in vitro pharmacological experiments with the drug-containing animal serum. The method has the same convenience as a typical in vitro experiment. Seropharmacology also provides a bioactive metabolite with the true pharmacological potency, having undergone biotransformation in the body of the laboratory animal. Therefore, it can be employed to study the biological effects of CBC.

In the present study, drug-containing animal serum was prepared, and insight into the mechanism underlying the 
anti-tumor effect of $\mathrm{CBC}$ was gained using the seropharmacological method.

\section{Materials and methods}

Drugs and reagents. CBC (Shaanxi Huaxi Pharmaceutical Co., Ltd., Baoji, China) consists of 11 traditional Chinese drugs including Mylabris phalerata extract (banmao), radix ginseng, radix astragali, radix acanthopanax senticosus, Rhizomasparganii, Scutellaria barbata, Curcuma zedoaria, Cornus officinalis, Ligustrum lucidum ait. and Herba galii aparinis extracts, andradix glycyrrhizae. A total of one capsule of $\mathrm{CBC}$ was dissolved in $1 \mathrm{ml}$ of PBS.

RPMI-1640 medium and fetal bovine serum (FBS) were obtained from Gibco (Thermo Fisher Scientific, Inc., Waltham, MA, USA). 4-(2-hydroxyethyl)-1-piperazineethanesulfonic acid, propidium iodide (PI), RNase, trypsin and 3-(4,5-dimethylthiazol-2-yl)-5-(3-carboxymethox yphenyl)-2-(4-sulfophenyl)-2H-tetrazolium (MTS) were from Sigma-Aldrich (Merck KGaA, Darmstadt, Germany). The Annexin V-Fluorescein Isothiocyanate Apoptosis Detection kit I was obtained from BD Pharmingen (San Diego, CA, USA).

Cell culture. K562 and HL60 human leukemia cells were obtained from the Institute of Biochemistry and Cell Biology, Chinese Academy of Sciences (Shanghai, China). Cells were maintained in RPMI-1640 medium supplemented with $10 \% \mathrm{FBS}, 100 \mathrm{U} / \mathrm{ml}$ penicillin and $100 \mu \mathrm{g} / \mathrm{ml}$ streptomycin in $5 \% \mathrm{CO}_{2}$ at $37^{\circ} \mathrm{C}$. At confluency, the cells were harvested with $0.25 \%$ trypsin in EDTA, counted and seeded. Confluent cells were used for the present study.

Preparation of rat sera. The animal experiments were performed according to the Guidelines for the Care and Use of Laboratory Animals (Zhejiang University, Zhejiang, China). The present study was approved by the Ethics Committee of The First Affiliated Hospital, College of Medicine, Zhejiang University. Female Wistar rats weighing 200-250 g, aged 5-6 months were provided by the Shanghai Research Center for Model Organisms (China), and housed in a room with $22-25^{\circ} \mathrm{C}$ temperature, $50-60 \%$ relative humidity and a $12 \mathrm{~h}$ light/12 h dark cycle. All animals had free access to food and water. A total of 16 rats were used for drug containing serum preparation. Rats were randomly divided into vehicle control $(n=8)$ and $\mathrm{CBC}(\mathrm{n}=8)$ groups, and intragastrical administration of PBS and CBC (3x rat weight $/ 65 \mathrm{~kg}$ ) was then performed for 7 days. Blood was obtained from the heart of the rats (before sacrificing) following the last administration and serum was acquired by blood centrifugation at 2,000 x g for $20 \mathrm{~min}$ at $4^{\circ} \mathrm{C}$. Following two filtration procedures with $0.22-\mu \mathrm{m}$ cellulose acetate membranes, the sera were bottled, heated to inactivate at $56^{\circ} \mathrm{C}$ for $30 \mathrm{~min}$ and stored at $-20^{\circ} \mathrm{C}$ until use.

Assessment of relative viability with an MTS assay. K562 and HL60 cells were seeded into a 96-well plate at a density of $10^{4}$ cells/well and cultured in RPMI-1640 containing $10 \%$ drug-containing serum, control serum or control serum with $10 \mu \mathrm{g} / \mathrm{ml}$ norcantharidin (Shanghai Tauto Biotech Co., Ltd.,
Shanghai, China) for up to $72 \mathrm{~h}$ in the previously described conditions. The relative viability of the cells was quantified by measuring the amount of MTS converted by the cells. After 24, 48 or $72 \mathrm{~h}$ incubation with the treatment, $20 \mu \mathrm{l}$ MTS was added to each well, incubated for another $2 \mathrm{~h}$ at $37^{\circ} \mathrm{C}$ and $5 \% \mathrm{CO}_{2}$, and $25 \mu \mathrm{l} /$ well of $10 \%$ SDS was subsequently added. The absorbance of each plate at $490 \mathrm{~nm}$ was measured with a spectrophotometer. All experiments were performed $\geq 3$ times.

Detection of apoptosis with Annexin V-fluorescein isothiocyanate (FITC)/PI staining. The rate of apoptosis in the K562 and HL60 cells was detected using flow cytometry. The cells were maintained in RPMI-1640 medium with $10 \%$ drug-containing or control serum for $72 \mathrm{~h}$ in the previously described conditions. Subsequently, cells were harvested, washed twice with PBS and resuspended in the binding buffer to a final concentration of $10^{6}$ cells $/ \mathrm{ml}$. Following the addition of Annexin V-FITC/PI solution, the cells were kept in the dark for $20 \mathrm{~min}$ at room temperature to stain the damaged DNA of the apoptotic cells. Subsequent to filtration using a $300-\mu \mathrm{m}$ mesh strainer, the cells underwent apoptosis analysis by flow cytometry (BD Biosciences, Franklin Lakes, NJ, USA; Canto II). All experiments were performed $\geq 3$ times.

Cell cycle distribution assessment. Subsequent to incubating the K562 and HL60 cells with drug-containing or control serum for $72 \mathrm{~h}$, the harvested cells were seeded to a concentration of $10^{6}$ cells $/ \mathrm{ml}$, fixed with $70 \%$ ice-cold ethanol, incubated with $0.25 \%$ RNase at $37^{\circ} \mathrm{C}$ for $30 \mathrm{~min}$ and stained with $50 \mu \mathrm{g} / \mathrm{ml}$ PI according to the manufacturer's protocol. Subsequent to filtration with a $300-\mu \mathrm{m}$ mesh strainer, the cells underwent cell cycle analysis by flow cytometry. All experiments were performed independently $\geq 3$ times.

Reverse transcription-quantitative polymerase chain reaction (RT-qPCR). Subsequent to incubating human leukemia cell lines with drug-containing or control serum for $72 \mathrm{~h}$, the total RNA from the harvested cells was extracted using TRIzol reagent (Invitrogen; Thermo Fisher Scientific, Inc.) according to the manufacturer's protocol. RT-qPCR was performed with a One Step SYBR ${ }^{\circledR}$ PrimeScript $^{\mathrm{TM}}$ RT-qPCR kit (Takara Biotechnology Co., Ltd., Dalian, China) and an iQ5 Real-time PCR Detection system (Bio-Rad Laboratories, Inc., Hercules, CA, USA). The procedure was as follows: $95^{\circ} \mathrm{C}$ for $1 \mathrm{~min}$ for 40 cycles $\left(95^{\circ} \mathrm{C}\right.$ for $10 \mathrm{sec}$ and $60^{\circ} \mathrm{C} 1 \mathrm{~min}$ ). The mRNA of VEGF-A and chemotactic and inflammatory genes was detected with specific primers (Sangon Biotech Co., Ltd, Shanghai, China), as listed in Table I. Expression of the GAPDH gene was assessed simultaneously in all samples as an internal control. Relative gene expression was determined using the $2^{-\Delta \Delta \mathrm{Cq}}$ method (7). All examinations were repeated three times.

Statistical analysis. All statistical analyses were performed using SPSS 17.0 software (SPSS Inc., Chicago, IL, USA). Data are presented as the mean \pm standard deviation. A Student's $t$ test was employed to identify the significance of the difference between groups. $\mathrm{P}<0.05$ was considered to indicate a statistically significant difference. 


\section{Results}

Treatment with $C B C$-containing serum reduces the relative viability of human leukemia cells. As demonstrated in Fig. 1, the relative viability of human leukemia K562 ( $\mathrm{P}=0.00198$; Fig. 1A) and HL60 ( $\mathrm{P}=0.00266$; Fig. 1B) cells at $72 \mathrm{~h}$ were significantly reduced by treatment with $\mathrm{CBC}$-containing serum compared with treatment with control serum. The relative viability rates of K562 and HL60 cells treated with CBC-containing serum at $72 \mathrm{~h}$ were $80.35 \pm 2.64$ and $76.43 \pm 2.31 \%$, respectively.

Treatment with CBC-containing serum increases the rate of apoptosis in human leukemia cells. Subsequent to incubating with CBC-containing or control serum for $72 \mathrm{~h}$, the rate of apoptosis in HL60 and K562 cells was analyzed using flow cytometry (Fig. 2). In HL60 cells, the apoptosis rate was $9.10 \pm 2.01 \%$ for FBS-treated cells (Fig. 2A), $18.33 \pm 3.13 \%$ for the control serum-treated cells (Fig. 2B) and $28.99 \pm 1.33 \%$ for the CBC-containing serum-treated cells (Fig. 2C). In K562 cells, a similar trend to that observed in HL60 cells was identified; the rate was $6.88 \pm 1.12 \%$ for FBS treated cells (Fig. 2D), $10.25 \pm 3.22 \%$ for control serum-treated cells (Fig. 2E) and $31.38 \pm 4.45 \%$ for the CBC-containing serum-treated cells (Fig. 2F).

Treatment with CBC-containing serum alters the cell cycle distribution of human leukemia cells. Subsequent to incubation with CBC-containing serum, a cell cycle arrest was observed in HL60 and K562 cells at 48-72 h (Fig. 3). For HL60 cells, the proportion of $\mathrm{S}$ phase cells was $19.22 \%$ in CBC-containing serum-treated group and $22.33 \%$ in the control serum group (Fig. 3C). In K562 cells, the ratio of S phase cells was $15.42 \%$ in $\mathrm{CBC}$-containing serum-treated group and $27.79 \%$ in the control serum group (Fig. 3F).

Treatment with CBC-containing serum decreases the $m R N A$ expression of VEGF-A in human leukemia cells. As VEGF-A is an important protein in the promotion of angiogenesis, its mRNA expression level was assessed using RT-qPCR. As demonstrated in Fig. 4, decreased gene expression of VEGF-A mRNA was observed in HL60 and K562 cells treated by CBC-containing serum; the fold changes were 5.67 for K562 cells (Fig. 4A) and 2.7 for HL60 cells (Fig. 4B).

Effect of CBC-containing serum on the mRNA expression of chemotactic and inflammatory genes in human leukemia cells. The mRNA expression of chemotactic and inflammatory genes, including $\mathrm{C}-\mathrm{C}$ motif chemokine receptor (CCR)2, C-C motif chemokine ligand (CCL)5, CCR4, Dickkopf 3 (DDK3), high mobility group box (HMGB)2, CCR1, CCR5, C-X-C motif chemokine ligand (CXCL)1, DEAD-box helicase (DDX)1, cyclin D1 (CCND1) and interleukin (IL)-6, were detected using RT-qPCR. As demonstrated by Fig. 5, decreased mRNA expression of CCR2, CCR4, DDK3, HMGB2, CCR1, CCR5 and DDX1 and increased expression of CXCL1 were identified in HL60 cells following treatment with CBC-containing serum (Fig. 5A). Decreased mRNA expression of CCR2, CCL5, CCR4, DDK3, CCR5, DDX1, CCND1 and IL-6 was identified in K562 cells treated with CBC-containing serum (Fig. 5B).
Table I. The primers used in the reverse transcription-quantitative polymerase chain reaction for detection of relative expression levels of genes.

\begin{tabular}{|c|c|}
\hline Genes & Primers $\left(5^{\prime}\right.$ to $\left.3^{\prime}\right)$ \\
\hline VEGF-F & CGCAGCTACTGCCATCCAAT \\
\hline VEGF-R & GTGAGGTTTGATCCGCATAATCT \\
\hline CCR1-F & TCCTGCTGACGATTGACAGGTA \\
\hline CCR1-R & GTGCCCGCAAGGCAAAC \\
\hline CCR2-F & GCGTTTAATCACATTCGAGTGTTT \\
\hline CCR2-R & CCACTGGCAAATTAGGGAACAA \\
\hline CCR4-F & CAATACTGTGGGCTCCTCCAA \\
\hline CCR4-R & ATCCATGGTGGACTGCGTGTA \\
\hline CCR5-F & GCTGGTCATCCTCATCCTGATAA \\
\hline CCR5-R & ATGGCCAGGTTGAGCAGGTA \\
\hline CCL5-F & TCCCGAACCCATTTCTTCTCT \\
\hline CCL5-R & CCCAGCAGTCGTCTTTGTCA \\
\hline CXCL1-F & AGGGAATTCACCCCAAGAAC \\
\hline CXCL1-R & ACTATGGGGGATGCAGGATT \\
\hline CCND1-F & GGCGGAGGAGAACAAACAGA \\
\hline CCND1-R & TGGCACAAGAGGCAACGA \\
\hline DDX1-F & AGCCAAGATGCAGGAAAGATG \\
\hline DDX1-R & GCTATAAAGGCCATGTGGATATTTTG \\
\hline DDK3-F & GAAACTGCTCTGGTCTTCACTAGCT \\
\hline DDK3-R & CTCCTCGTCCATCAGGGATCT \\
\hline HMGB2-F & CTTGGCACGATATGCAGCAA \\
\hline HMGB2-R & CAGCCAAAGATAAACAACCATATGA \\
\hline IL6-F & TGCGTCCGTAGTTTCCTTCT \\
\hline IL6-R & GCCTCAGACATCTCCAGTCC \\
\hline
\end{tabular}

F, forward; R, reverse.

\section{Discussion}

Seropharmacology is a novel method for the pharmacological study of Chinese materia medica (8). It has the advantages of in vitro experiment, including convenient control of the experimental conditions and the exclusion of interference of internal factors, which facilitate the in-depth study of the mechanism of action for a drug. Seropharmacology reflects the drug metabolism process (including absorption, distribution, metabolism and excretion) of the body, and the drug in the animal serum is in the form of bioactive metabolites with the real pharmacological functions of interest. A number of substances (including secreted cell factor, hormones, antibodies and complement) induced by drug in the body are then retained in the animal serum and can be applied to an in vitro experiment, important for the investigation of indirect effects of a drug. In addition, Chinese herbal preparation is likely to be affected by various factors (including chemicals, ions, $\mathrm{pH}$, purity and osmotic pressure) that could result in changes of the outcome of an in vitro experiment. Therefore, seropharmacology is quite suitable for pharmacological study on Chinese herbal preparation $(9,10)$. For this reason, CBC-containing serum was prepared for the present study. 
A

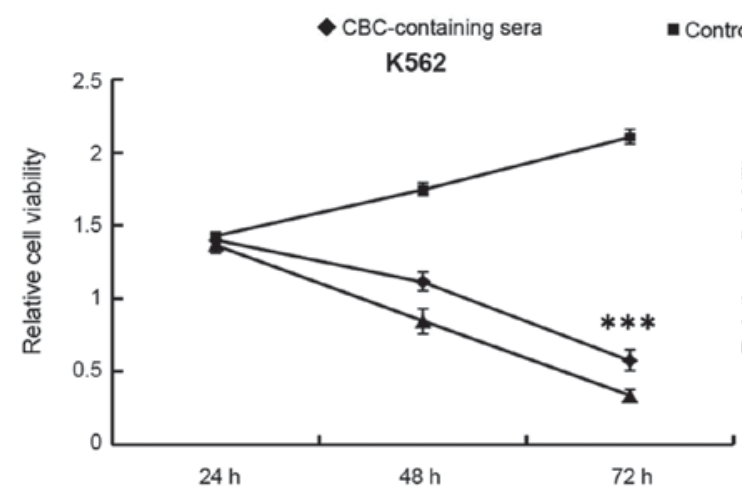

B



Figure 1. Effects of CBC-containing rat serum on the viability of human leukemia cell lines (A) K562 and (B) HL60. ${ }^{* * *} \mathrm{P}<0.01$ vs. control serum-treated cells. $\mathrm{CBC}$, compound banmao capsule. Error bars represent the standard error of absorbance values of 6 wells.
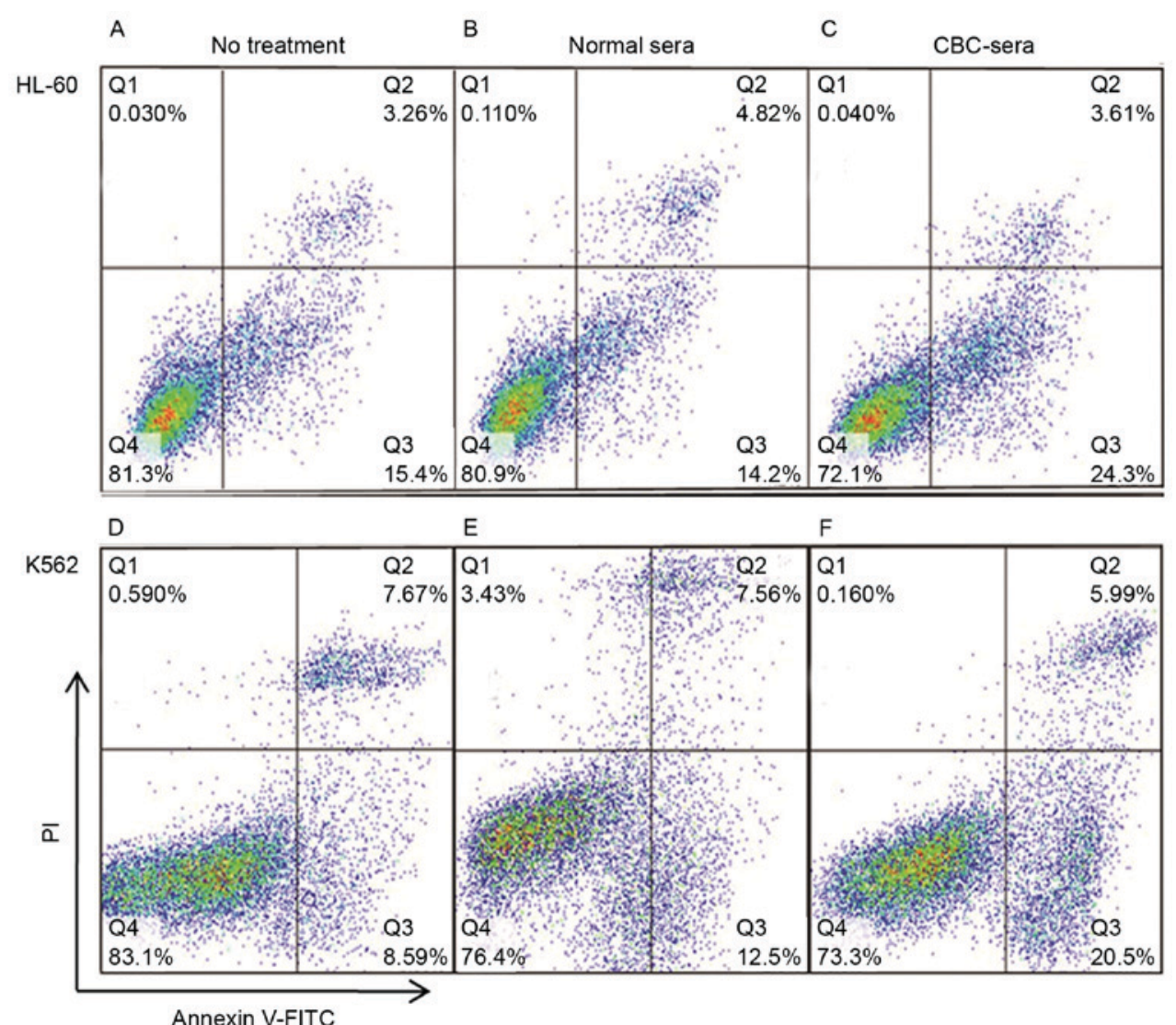

Figure 2. Effects of CBC-containing rat serum on the apoptosis of human leukemia cell lines HL60 and K562. HL60 cells treated with (A) FBS (no treatment), (B) control rat serum or (C) CBC-containing rat serum; K562 cells treated with (D) FBS, (E) control rat serum or (F) CBC-containing rat serum. CBC, compound banmao capsule; FBS, fetal calf serum; PI, propidium iodide; FITC, fluorescein isothiocyanate.

CBC is a traditional Chinese medicinal preparation consisting of 11 TCM drugs. Among these 11 drugs, banmao and radix acanthopanax senticosus have been widely applied in TCM cancer therapy (11). Banmao is the dried body of the Chinese blister beetle, which has been used from antiquity to the present day in folk medicine $(12,13)$. Banmao can directly inhibit the proliferation of tumor cells. The active constituent of Banmao is cantharidin, which occurs in the dried body at a concentration of $0.6-1.9 \%$. A previous study demonstrated that cantharidin is a strong protein phosphatase and phosphatase
2A inhibitor, and can be used to inhibit cAMP phosphodiesterase activity in hepatoma cells (14). Cantharidin has been used to treat various types of tumor, including bowel (15), mammary (16) and gallbladder (17) cancer and leukemia, through inhibiting cellular proliferation and angiogenesis, and inducing cell cycle arrest and apoptosis. In primary hepatic carcinoma cells, cantharidin has been demonstrated to exhibit greater cytotoxic effects against tumor cells compared with those observed in normal cells, and may induce a G2/M cell cycle arrest in carcinoma cells (18). Dorn et al (19) reported 

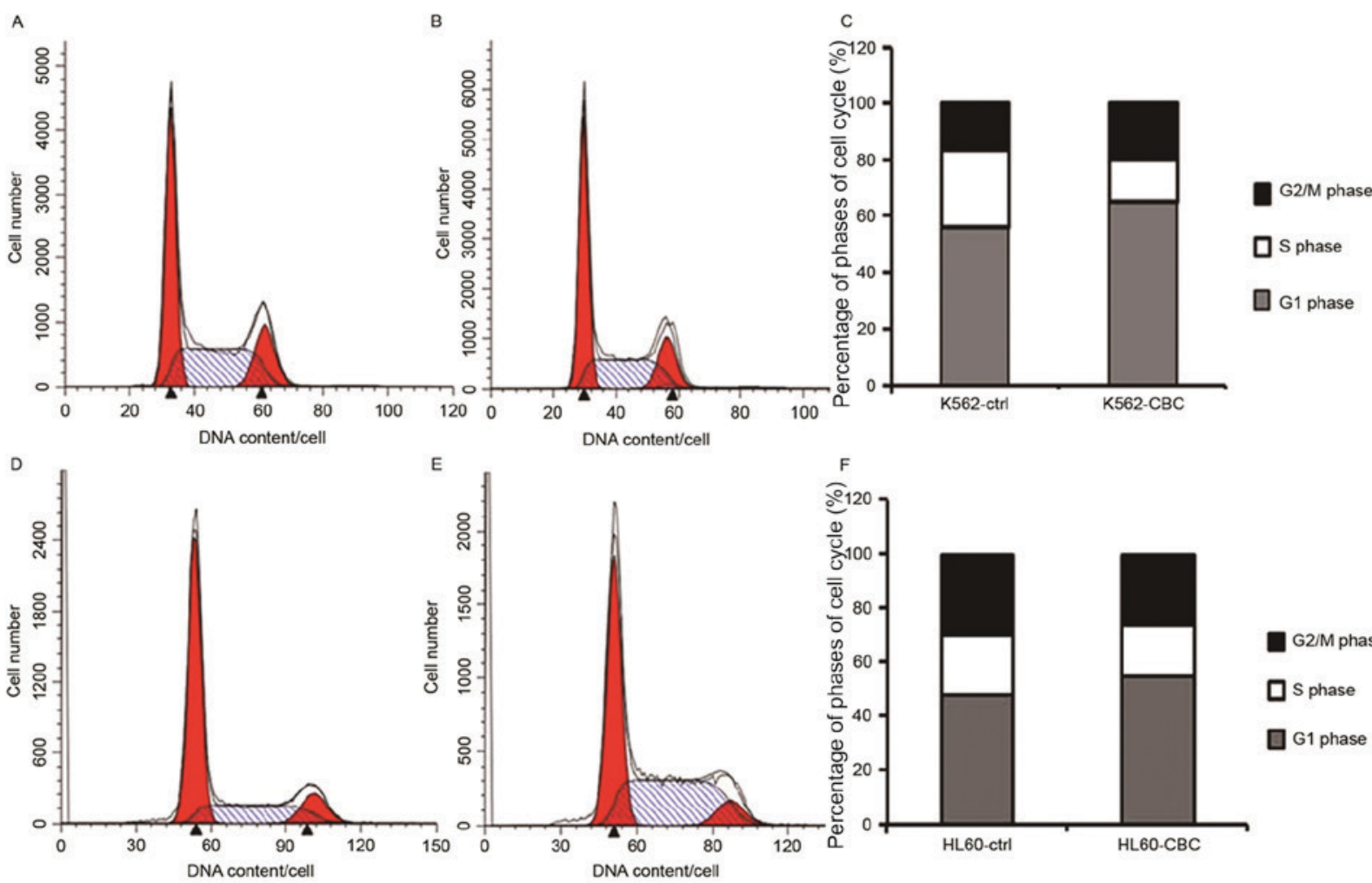

Figure 3. Effects of CBC-containing rat serum on the cell cycle of human leukemia cell lines HL60 and K562. Subsequent to treatment with CBC-containing or vehicle control rat serum, the cells were processed with cell cycle analysis by flow cytometry. K562 cells treated with (A) control rat serum or (B) CBC-containing rat serum; (C) histogram of the differences in cell cycle distribution between (A) and (B). HL60 cells treated with (D) control rat serum or (E) CBC-containing rat serum; (F) histogram of the differences in cell cycle distribution between (D) and (E). CBC, compound banmao capsule; ctrl, control.

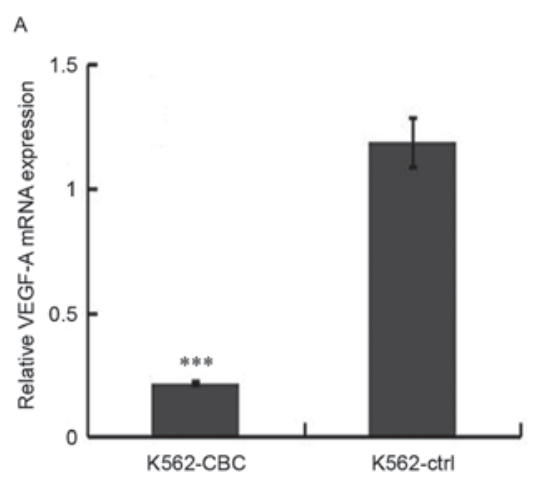

B



Figure 4. Effects of CBC-containing rat serum on the mRNA expression of VEGF-A in human leukemia cell lines. The differences in VEGF-A mRNA expression between cells treated with control rat serum or $\mathrm{CBC}$-containing rat serum were assessed in (A) K562 cells and (B) HL60 cells. ${ }^{* * *} \mathrm{P}<0.01$ compared with the control. Error bars represent the standard error of triplicate wells. CBC, compound banmao capsule; VEGF-A, vascular endothelial growth factor $\mathrm{A}$.
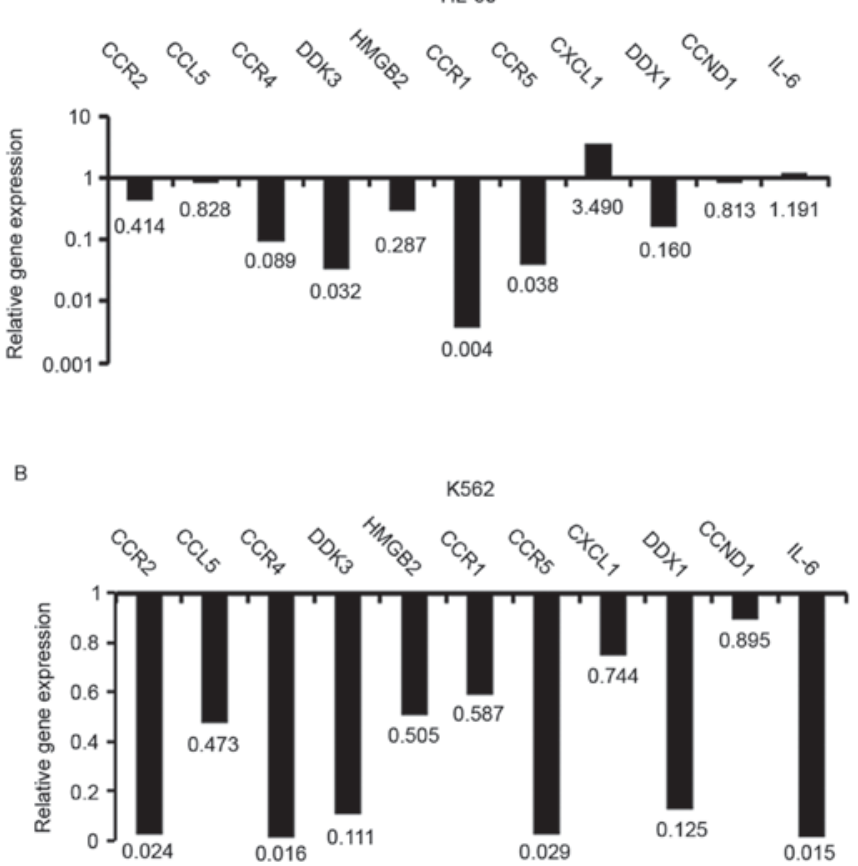

Figure 5. Effects of CBC-containing rat serum on the expression of chemotactic and inflammatory genes in human leukemia cell lines. The fold changes of mRNA (CBC serum/control) in (A) HL60 cells and (B) K562 cells subsequent to $\mathrm{CBC}$-containing serum treatment. $\mathrm{CBC}$, compound banmao capsule; CCR, C-C motif chemokine receptor; $\mathrm{CCL}, \mathrm{C}-\mathrm{C}$ motif chemokine ligand; DDK, Dickkopf; HMGB, high mobility group box; CXCL, C-X-C motif chemokine ligand; DDX, DEAD box helicase; CCND, cyclin D1; IL, interleukin. 
that cantharidin induced apoptosis, inhibited proliferation and caused cell cycle arrest in Jurkat cells. Cantharidin has also been reported to exhibit an antitumor effect on acute and chronic myeloid leukemia cells through the induction of apoptosis and the inhibition of proliferation (20).

Distinct from the anticancer mechanism of Banmao, stimulation $(21,22)$ and suppression $(23,24)$ of the immune response have been proposed as mechanisms for the antitumor effect of radix acanthopanax senticosus, a plant stem extract, the main anticancer constituents of which are glucosides and polysaccharides. Yoon et al (25) investigated the antitumor activity of an aqueous acanthopanax senticosus solution; its anti-tumor effect was reported to be associated with the activation of macrophages and natural killer cells (25). In TCM clinical treatment, banmao is used to cure patients of their cancer, whereas acanthopanax senticosus is used for cancer prevention (26). In the present study, a significant reduction in relative cell viability, an increase in the rate of apoptosis, and a $G_{0} / G_{1}$ cell cycle arrest were identified. Therefore, in addition to previous reports that $\mathrm{CBC}$-containing serum can exert an antitumor effect on liver carcinoma cells $(27,28)$, its efficacy on leukemia cells has now been demonstrated.

In the present study, a decreasing level of VEGF-A, the main subtype of VEGF, was identified in HL60 and K562 cells subsequent to treatment with $\mathrm{CBC}$-containing serum. According to previous reports, VEGF-associated angiogenesis performs a critical role in the pathogenesis of hematopoietic malignancies $(29,30)$. VEGF expression may mediate apoptosis resistance and thus, radiotherapy resistance (28). Therefore, an effect against VEGF could be an important mechanism for the treatment of leukemia. Our previous study demonstrated that angiogenesis performed a critical role in the pathological process of acute leukemia, and that the expression level of VEGF was closely associated with the degree of angiogenesis and the disease progression in patients with leukemia (31). At present, a number of drugs targeting angiogenesis have been successful in the treatment of acute and chronic myeloid leukemia (32).

A number of studies (33-35) have demonstrated that inflammatory and chemotactic genes are closely associated with hematopoietic malignancies, which is why it was considered necessary to assess the status of inflammatory and chemotactic genes in the present study. Downregulation of chemokine gene mRNA expression was identified in HL60 and $\mathrm{K} 562$ cells treated with CBC-containing serum; however, differential expression of IL6 was identified between HL60 and K562 cells. This may be due to the different types of leukemia represented by HL60 and K562, as HL60 was established from acute myeloid leukemia and K562 from chronic myeloid leukemia.

In conclusion, a seropharmacological method was used to prepare $\mathrm{CBC}$-containing rat serum to evaluate its effect on human leukemia HL60 and K562 cells. A reduction in cell viability, increased apoptosis and cell cycle arrest were all observed following treatment with CBC-containing serum. Furthermore, the mRNA expression of VEGF-A and chemotactic and inflammatory genes was attenuated following treatment with $\mathrm{CBC}$-containing serum. Additional studies are required to investigate the efficacy of the combination of $\mathrm{CBC}$ with other anticancer drugs in the clinical practice.

\section{Acknowledgements}

The present study was supported by Chinese Medicine Scientific Research Foundation of Zhejiang Province (grant no. 2010B501720), Zhejiang Provincial Department of Education (grant no. Y201120523) and Zhejiang Provincial Administration of Traditional Chinese Medicine (grant no. Y201120523).

\section{References}

1. Vardiman JW: The World Health Organization (WHO) classification of tumors of the hematopoietic and lymphoid tissues: An overview with emphasis on the myeloid neoplasms. Chem Biol Interact 184: 16-20, 2010.

2. Li FF, Yi S, Wen L, He J, Yang LJ, Zhao J, Zhang BP, Cui GH and Chen Y: Oridonin induces NPM mutant protein translocation and apoptosis in NPM1c+ acute myeloid leukemia cells in vitro. Acta Pharmacol Sin 35: 806-813, 2014.

3. Hu XM, Yuan B, Tanaka S, Song MM, Onda K, Tohyama K, Zhou AX, Toyoda $\mathrm{H}$ and Hirano T: Arsenic disulfide-triggered apoptosis and erythroid differentiation in myelodysplastic syndrome and acute myeloid leukemia cell lines. Hematology 19: 352-360, 2014.

4. Man S, Gao W, Wei C and Liu C: Anticancer drugs from traditional toxic Chinese medicines. Phytother Res 26: 1449-1465, 2012.

5. Liu D and Chen Z: The effects of cantharidin and cantharidin derivates on tumour cells. Anticancer Agents Med Chem 9: 392-396, 2009.

6. $\mathrm{Xu} \mathrm{H}, \mathrm{Wu} \mathrm{Q}$, Peng $\mathrm{C}$ and Zhou L: Study on the antiviral activity of San Huang Yi Gan Capsule against hepatitis B virus with seropharmacological method. BMC Complement Altern Med 13: 239, 2013

7. Livak KJ and Schmittgen TD: Analysis of relative gene expression data using real-time quantitative PCR and the 2(-Delta Delta C(T)) Method. Methods 25: 402-408, 2001.

8. Bochu W, Liancai Z and Qi C: Primary study on the application of Serum Pharmacology in Chinese traditional medicine. Colloids Surf B Biointerfaces 43: 194-197, 2005.

9. Wu Q, Rong X, Huang P, Han J and Xu H: Study on inhibitory actions of san huang yi gan capsule (SHYGC) on HBeAg with seropharmacological method. Zhong Yao Cai 23: 2 75-278, 2000 (In Chinese).

10. Zhang YH, Liu JT, Wen BY and Liu N: Mechanisms of inhibiting proliferation of vascular smooth muscle cells by serum of rats treated with Dahuang Zhechong pill. J Ethnopharmacol 124: 125-129, 2009.

11. Han SB, Yoon YD, Ahn HJ, Lee HS, Lee CW, Yoon WK, Park SK and Kim HM: Toll-like receptor-mediated activation of $\mathrm{B}$ cells and macrophages by polysaccharide isolated from cell culture of Acanthopanax senticosus. Int Immunopharmacol 3: 1301-1312, 2003

12. Wang GS: Medical uses of mylabris in ancient China and recent studies. J Ethnopharmacol 26: 147-162, 1989.

13. Tagwireyi D,BallDE,Loga PJ and Moyo S: Cantharidin poisoning due to 'Blister beetle' ingestion. Toxicon 38: 1865-1869, 2000.

14. Graziano MJ, Pessah IN, Matsuzawa M and Casida JE: Partial characterization of specific cantharidin binding sites in mouse tissues. Mol Pharmacol 33: 706-712, 1988.

15. Peng F, Wei YQ, Tian L, Yang L, Zhao X, Lu Y, Mao YQ, Kan B, Lei S, Wang GS, et al: Induction of apoptosis by norcantharidin in human colorectal carcinoma cell lines: Involvement of the CD95 receptor/ligand. J Cancer Res Clin Oncol 128: 223-230, 2002.

16. Huang Y, Liu Q, Liu K, Yagasaki K and Zhang G: Suppression of growth of highly-metastatic human breast cancer cells by norcantharidin and its mechanisms of action. Cytotechnology 59: 209, 2009.

17. Fan YZ, Fu JY, Zhao ZM and Chen CQ: Inhibitory effect of norcantharidin on the growth of human gallbladder carcinoma GBC-SD cells in vitro. Hepatobiliary Pancreat Dis Int 6: 72-80, 2007.

18. Huan SK, Lee HH, Liu DZ, Wu CC and Wang CC: Cantharidin-induced cytotoxicity and cyclooxygenase 2 expression in human bladder carcinoma cell line. Toxicology 223: 136-143, 2006. 
19. Dorn DC, Kou CA, Png KJ and Moore MA: The effect of cantharidins on leukemic stem cells. Int J Cancer 124: 2186-2199, 2009.

20. Yi SN, Wass J, Vincent P and Iland H: Inhibitory effect of norcantharidin on K562 human myeloid leukemia cells in vitro. Leuk Res 15: 883-886, 1991.

21. Schmeda-Hirschmann G, Villaseñor-García MM, Lozoya X and Puebla-Pérez AM: Immunomodulatory activity of Chilean Cyttaria species in mice with L5178Y lymphoma. J Ethnopharmacol 77: 253-257, 2001.

22. Schmolz MW, Sacher F and Aicher B: The synthesis of Rantes, G-CSF, IL-4, IL-5, IL-6, IL-12 and IL-13 in human whole-blood cultures is modulated by an extract from Eleutherococcus senticosus L. roots. Phytother Res 15: 268-270, 2001.

23. Jeong HJ, Koo HN, Myung NI, Shin MK, Kim JW, Kim DK, Kim KS, Kim HM and Lee YM: Inhibitory effects of mast cell-mediated allergic reactions by cell cultured Siberian Ginseng. Immunopharmacol Immunotoxicol 23: 107-117, 2001.

24. Yi JM, Kim MS, Seo SW, Lee KN, Yook CS and Kim HM: Acanthopanax senticosus root inhibits mast cell-dependent anaphylaxis. Clin Chim Acta 312: 163-168, 2001.

25. Yoon TJ, Yoo YC, Lee SW, Shin KS, Choi WH, Hwang SH, Ha ES, Jo SK, Kim SH and Park WM: Anti-metastatic activity of Acanthopanax senticosus extract and its possible immunological mechanism of action. J Ethnopharmacol 93: 247-253, 2004

26. Wang Q, Wang Y, Liu R, Yan X, Li Y, Fu H, Bi K and Li Q: Comparison of the effects of Mylabris and Acanthopanax senticosus on promising cancer marker polyamines in plasma of a Hepatoma-22 mouse model using HPLC-ESI-MS. Biomed Chromatogr 27: 208-215, 2013.

27. Chang C, Zhu YQ, Mei JJ, Liu SQ and Luo J: Involvement of mitochondrial pathway in NCTD-induced cytotoxicity in human hepG2 cells. J Exp Clin Cancer Res 29: 145, 2010.
28. Zheng LH, Bao YL, Wu Y, Yu CL, Meng X and Li YX: Cantharidin reverses multidrug resistance of human hepatoma HepG2/ADM cells via down-regulation of P-glycoprotein expression. Cancer Lett 272: 102-109, 2008.

29. Avramis IA, Kwock R and Avramis VI: Taxotere and vincristine inhibit the secretion of the angiogenesis inducing vascular endothelial growth factor (VEGF) by wild-type and drug-resistant human leukemia T-cell lines. Anticancer Res 21: 2281-2286, 2001.

30. Katoh O, Tauchi H, Kawaishi K, Kimura A and Satow Y: Expression of the vascular endothelial growth factor (VEGF) receptor gene, KDR, in hematopoietic cells and inhibitory effect of VEGF on apoptotic cell death caused by ionizing radiation. Cancer Res 55: 5687-5692, 1995.

31. Ye X, Wang LJ, Lin MF and Ding W: The clinical significance of angiogenesis in the bone marrow of acute leukemia patients. Zhonghua Nei Ke Za Zhi 42: 486-489, 2003 (In Chinese).

32. Ye XJ and Lin MF: Homoharringtonine induces apoptosis of endothelium and down-regulates VEGF expression of K562 cells. J Zhejiang Univ Sci 5: 230-234, 2004.

33. Aggarwal BB, Shishodia S, Sandur SK, Pandey MK and Sethi G: Inflammation and cancer: How hot is the link? Biochem Pharmacol 72: 1605-1621, 2006.

34. Gasparini C, Celeghini C, Monasta L and Zauli G: NF- $\kappa B$ pathways in hematological malignancies. Cell Mol Life Sci 71: 2083-2102, 2014.

35. Candido J and Hagemann T: Cancer-related inflammation. J Clin Immunol 33 (Suppl 1): S79-S84, 2013. 